\title{
Home Ownership, Job Duration, and Wages
}

Munch, Jakob Roland; Rosholm, Michael; Svarer, Michael

Publication date:

2006

Document version

Publisher's PDF, also known as Version of record

Citation for published version (APA):

Munch, J. R., Rosholm, M., \& Svarer, M. (2006). Home Ownership, Job Duration, and Wages. Centre for Applied Microeconometrics. Department of Economics, University of Copenhagen. 


\section{CAM}

\section{CAM}

Centre for Applied

Microeconometrics

Department of Economics

University of Copenhagen

http://www.econ.ku.dk/CAMI

Home Ownership, Job Duration, and Wages

Jakob Roland Munch, Michael Rosholm \& Michael Svarer

2006-08 


\title{
Home Ownership, Job Duration, and Wages*
}

\author{
Jakob Roland Munch \\ University of Copenhagen, \\ CEBR and EPRU
}

\author{
Michael Rosholm \\ Department of Economics \\ University of Aarhus
}

\author{
Michael Svarer \\ Department of Economics \\ University of Aarhus
}

\begin{abstract}
We investigate the impact of home ownership on individual job mobility and wages in Denmark. We find that home ownership has a negative impact on job-tojob mobility both in terms of transition into new local jobs and new jobs outside the local labour market. In addition, there is a clear negative effect of home ownership on the unemployment risk and a positive impact on wages. These results are robust to different strategies for correcting for the possible endogeneity of the home owner variable.
\end{abstract}

Keywords: Home ownership, job mobility, duration model.

JEL Classification: J6, R2

*Financial support from the Danish Social Science Research Council is gratefully acknowledged. Michael Svarer thanks the Danish National Research Foundation for support through its grant to CAM. We also thank Namkee Ahn, Harminder Battu, Thomas de Graff, Ada Ma, Euan Phimister, Michiel Van Leuvensteijn, and Aico van Vuuren for very helpful comments. We are also grateful to Birgitte Højklint for reading the manuscript. The usual disclaimer applies. 


\section{Introduction}

In a recent survey of the micro-level consequences of home ownership, Dietz \& Haurin (2003) found overwhelming evidence of positive externalities of home ownership. These positive effects range from home owners being more environmentally conscious over housing markets for owners appearing to suffer less discrimination than renting markets to home ownership being linked with better physical and mental health. Such externalities seem to support the favourable tax treatment of the capital invested in homes received by home owners (see Hendershott \& White (2000)). On the other hand, Oswald (1996) presents evidence that the unemployment rate and the share of home owners are positively correlated for a number of countries and regions. The proposed mechanism is that home owners are much less mobile than renters due to costs associated with buying and selling their home, and so they are relatively inflexible in the labour market. Thus, if the home owner share is high, the work force is immobile, which tends to give higher structural unemployment due to insufficient supply of labour. In his original work, Oswald (1996) presented evidence showing that countries or regions with a 10 percentage points higher share of home owners have a two percentage points higher unemployment rate. This relationship has been confirmed by Nickell \& Layard (1999) and Green \& Hendershott (2001b) also using macro data. These findings have inspired a number of papers investigating the impact of home ownership on labour market outcomes like unemployment duration, job duration and wages. In the present paper, we focus on the latter two outcomes.

In relation to Oswald's hypothesis, a central question is whether home owners are more likely to be unemployed? Munch et al. (2006) show that home owners overall have shorter unemployment spells than renters, even after correcting for the possible endogeneity of home owner status. However, they also find that home owners are less mobile in the sense that unemployed owners have a lower transition rate into jobs outside the local labour market, thus offering some support for the proposed mechanism behind Oswald's hypothesis. This effect is, however, dominated by a stronger positive effect on the transition rate into jobs in the local labour market. 
Having established that the duration of unemployment spells is shorter for home owners than for renters, it is still possible that employed home owners more often experience unemployment. That is, the duration of employment spells could be lower for home owners than for renters? A study on Dutch data by Van Leuvensteijn \& Koning (2004) suggests that this is not the case - in fact home owners have a lower unemployment risk. They also show that there is no impact of home ownership on the transition rate into a new job. ${ }^{1}$

Another important and related issue is whether home ownership affects wages. According to the survey by Dietz \& Haurin (2003) not much research exists on this relationship, but Coulson \& Fisher (2002) is an exception. Based on data from US Current Population Survey and PSID, they find that home owners have higher wages, shorter unemployment spells, and a lower probability of experiencing unemployment.

The purpose of the present paper is twofold. First, we offer some theoretical considerations concerning the impact of home ownership on job duration and wages. From a search theoretic perspective we argue that home owners stay longer in their jobs than renters because of reduced geographical mobility (due to mobility costs), and this in turn makes them more attractive for employers implying that owners are offered higher wages. Second, we empirically examine all these predictions using a rich Danish micro data set based on administrative registers. We estimate a competing risks duration model for job spells with a distinction between transitions into new jobs in the local labour market, new jobs outside the local labour market (where the distinction is made by realised housing mobility out of the local commuting area), and unemployment. In addition, we simultaneously estimate a standard human capital wage equation, thus allowing for an impact of home ownership on wages.

In empirical investigations of the effects of home ownership it is important to take into account the endogeneity of home ownership; if the selection process is not explicitly accounted for, the estimated parameters to the home ownership variable in the different equations cannot be interpreted causally. For example, in Coulson \& Fisher (2002) it

\footnotetext{
${ }^{1}$ They do not distinguish between local jobs and jobs outside the local labour market.
} 
is not clear whether the positive labour market outcomes found for home owners are causal or spurious, since the authors do not attempt to address the potential endogeniety of the home owner variable. According to Dietz \& Haurin (2003), this is a criticism that can be aimed at the majority of existing research on the micro-level consequences of home ownership, and they make a call for researchers in future work to put much more effort into identifying the causal linkage between home ownership and the outcomes of interest. In our empirical analysis we explicitly model the selection process into home ownership, and we use two different identification strategies to check the robustness of our results. First, we follow the identification strategy of Munch et al. (2006), where multiple observations for some individuals in the sample can be exploited, that is, we exploit the panel structure of our data to identify the causal linkage between home ownership and the outcomes of interest. Second, we also follow a more standard instrumental variables approach along the lines of Van Leuvensteijn \& Koning (2004). Our empirical results are completely consistent with the theoretical predictions, and they are very robust to the different identification strategies employed.

The paper is organized as follows. The next section outlines some simple theoretical considerations about the link between home ownership and labour market outcomes. Section 3 describes the data set. Section 4 presents the empirical model and discusses identification issues. Section 5 presents the estimation results, and finally section 6 offers a brief conclusion.

\section{Home ownership and labour market outcomes}

In order to set the stage for the empirical analysis, we present a few theoretical considerations based on a search theoretical foundation. Munch et al. (2006) construct a search model for unemployed workers. Because home owners have higher costs of geographical mobility than renters, they set higher reservation wages for accepting job offers outside commuting distance (requiring a residential move) than renters. The resulting exit rates to employment outside the local labour market are therefore lower for home owners. On 
the other hand, the risk of eventually having to move lowers the reservation wages for home owners in the local labour market, thus giving them higher hazard rates for local jobs. Empirically, Munch et al. (2006) found evidence for both effects, but the latter effect strongly dominates the first one. That is, in general owners have shorter unemployment spells, but they are also less likely to leave unemployment for a job outside the local labour market.

In the present context, the focus is on employed workers. They may also look for jobs locally or outside the local labour market (requiring a residential move), and they may quit or lose the job and search as unemployed. Naturally, the analysis of unemployment spells implies that home owners are less likely to quit the job, because they have lower local labour market reservation wages than renters. Thus, home owners are ceteris paribus less likely to become unemployed than renters.

Assume, without loss of generality, that renters have no costs of mobility. Hence, for renters the reservation wage for any job is the current wage. Home owners must be compensated for the costs of moving, so their reservation wages for non-local jobs will exceed the current wage by the annuitized value of the mobility cost. However, the worker can always keep her old job, so the reservation wage for local jobs must be equal to the current wage. Hence, in a partial equilibrium analysis, we would straightforwardly conclude that employed home owners would be less likely to switch to jobs outside the local labour market than renters, and that they would be less likely to become unemployed.

However, when investigating employment spells, equilibrium considerations become more important; suppose employers take these facts into account in the wage setting process. Home owners are likely to stay longer in a given job than renters, because they are less likely to accept a non-local job. Therefore, the expected present discounted value of a job, which is occupied by a home owner, is larger than if it were occupied by a renter. Thus, employers may prefer to hire home owners ceteris paribus, and they may even set their wages somewhat higher than for renters, in order to attract them. Another argument for paying higher wages to home owners is that the incentives to invest in these workers in terms of enhancing their human capital by providing firm-specific training are 
higher than for renters, since the home owners have a longer expected duration in the firm. Consequently, the firm can (expect to) recoup more of its initial investment (see e.g. Rosholm \& Svarer (2004)) when training home owners than they can when training renters. This implies that employed home owners have higher productivity than employed renters, thus justifying higher wages for home owners.

In sum, based on these simple considerations we would expect employed home owners to

- become unemployed less often than renters (they have lower reservation wages in unemployment),

- accept job offers outside the local labour market less often than renters (due to mobility costs),

- accept local job offers less often than renters (they have more firm specific productivity), and

- earn higher wages than renters (same reason as above).

\section{Data and the Danish labour and housing markets}

The Danish labour market shares some characteristics with Anglo Saxon labour markets which are important in the context of this paper. The Danish labour market is very flexible due to weak employment protection, and as a consequence turnover rates are higher than in other continental European countries. At the same time, the labour market is highly unionised and the wage structure is very compressed. The geographical mobility of both employed and unemployed workers is modest, and regional migration rates are at the low end compared to other continental European countries, cf. OECD (2000) and Danish Economic Council (2002).

The Danish housing market is comprised of four different main segments, but in the analysis we will only distinguish between owners and non-owners. The largest part is 
owner-occupied housing, including more than $50 \%$ of all housing units. Private rental housing and social housing each constitute almost 20\%, and cooperative housing accounts for $6 \%$ of the housing market. It should be noted that the markets for private rental housing, social housing and cooperative housing are heavily regulated by rent controls. For the private rental market, Munch and Svarer (2002) show that rent control distorts mobility, as tenancy duration is longer the more regulated the rent of the dwelling is. However, average tenancy durations in these three non-owner segments of the housing market are still much lower than in owner-occupied housing units, which justifies our focus on owners and non-owners (henceforth denoted renters).

To investigate the causes behind mobility of employed workers in Denmark, a very rich data set, which is drawn from administrative registers, is employed. The data set covers $1 \%$ of the Danish population for the years 1993-2001. In each year, detailed information about the labour market states of all individuals along with information on socioeconomic characteristics is available. These socioeconomic variables are extracted from the integrated database for labour market research (IDA) and the income registers in Statistics Denmark. Of particular importance is the fact that a workplace identity is associated with each worker at the end of each year. A firm can have more than one workplace so if a worker changes between two workplaces within the same firm, then this is counted as a job change in the present analysis. Job spells are then straightforwardly constructed from successive years at the same workplace.

Here we are interested in the duration of job spells and transitions into new jobs and unemployment, and for the present purposes job spells are flow sampled such that only spells starting in 1993 and later are included in the analysis. The destination state for all spells that end before 2001 is known, and if job spells end with transitions into other states than a new job or unemployment (e.g. out of the labour force), or if spells are not completed by the end of 2001, they are treated as independently right censored observations. In addition, if job spells end because of a firm closure, they are also treated as independently right censored observations. ${ }^{2}$ All students with (student) jobs have been

\footnotetext{
${ }^{2}$ The reason for this treatment of individuals losing their job from plant closures is that we want to
} 
excluded from the sample. We operate with three different destination states from a job; unemployment, a new job in the local labour market, and a new job outside the local labour market.

The local labour markets are so-called commuting areas, which are defined such that the internal migration rate is $50 \%$ higher than the external migration rate, cf. Andersen (2000). The commuting areas are based on geographically connected municipalities, and the 275 municipalities in Denmark are merged into 51 such commuting areas. An employed worker is defined to find a new job outside the local labour market if he or she changes job and moves to another commuting area in the same year as the beginning of the new job spell. ${ }^{3}$

In the resulting data set there are 29,878 job spells for 17,297 individuals. Table 1 displays summary statistics for all explanatory variables. Self explanatory dummies for age, gender, the presence of children, the presence of two adults in the household, and education are included. Also, three geographic dummies are included to distinguish between the capital Copenhagen, 5 large cities, and all other localities (small city). Information on the hourly wage rate and years of working experience are also included. In the model for the hourly wage rate, we also include the elapsed duration of the job, denoted job tenure. In addition, Table 1 describes three variables that will act as exclusion restrictions, that is, they will enter the equation for the selection into home ownership but not the other equations in the analyses performed below. These are the proportion of home owners in the municipality of residence ${ }^{4}$, the proportion of home owners in the municipality of birth, and finally a dummy variable for the home owner status of the individual's parents in 1980

Insert Table 1 about here

There are $58 \%$ home owners in the sample, which is slightly above the proportion of home owners in the country. Presumably the over-representation is due to the selection investigate only job-worker separations that are, at least partly, determined by either the worker or the firm, not by exogenous forces.

${ }^{3}$ Exact moving dates are known for all individuals.

${ }^{4}$ This variable is also used by Van Leuvensteijn \& Koning (2004) as an exclusion restriction. 
of employed workers only, who are more likely to be home owners than those who are unemployed or outside the labour market. A comparison of home owners to renters reveals that home owners tend to be older, are more likely to have children, are less likely to live in Copenhagen, and likely to have more education, more working experience and more tenure, and to earn higher wages. This pattern is consistent with Coulson \& Fisher (2002), who finds that home owners have more favourable labour market outcomes than renters.

\section{Econometric model}

In order to investigate the impact of home ownership on job duration and wages, we formulate an empirical model for job duration, wages, and selection into home owner status simultaneously. The first step is to specify a competing risks duration model. We are specifically interested in addressing exits from employment to unemployment, to new jobs in the local labour market, and to new jobs outside the local labour market, where the distinction between local and non-local labour markets is made as described in the previous section.

We specify a duration model with a flexible non-parametric specification of the baseline hazard. To distinguish between different destinations we use a competing risks duration model. Even if there is access to a comprehensive data set there might still be some unobserved heterogeneity left, as no measures for e.g. ability or motivation are available. Therefore we attempt to capture unobserved worker characteristics by specifying a mixed proportional hazard model for the labour market transitions:

$$
\theta_{i}\left(t \mid x_{t}, v_{i}\right)=\lambda_{i}(t) \exp \left(\beta_{i}^{\prime} x_{t}+\gamma_{i} z_{t}+v_{i}\right)
$$

where $i=e l, e n, u$ indicates the different destination states for the transition (i.e., employment locally, employment outside the local labour market, and unemployment), $\lambda_{i}(t)$ is the baseline hazard capturing the time dependence for transitions into destination $i$, 
and $\exp \left(x_{t} \beta_{i}+v_{i}\right)$ is the systematic part giving the proportional effects of the timevarying home-ownership dummy, $z_{t}$, other observed and time-varying characteristics, $x_{t}$, and unobserved characteristics, $v_{i}$. All job spells that end with a transition to another state than one of the three described above (e.g. out of the labour force) are treated as independently right censored observations.

The annual observations in the data imply that the duration variable $T$ is grouped into $K+1$ intervals $\left\{\left[0, t_{1}\right),\left[t_{1}, t_{2}\right), . .,\left[t_{k}, \infty\right)\right\}$, which must be accounted for in the econometric specification. Following Kiefer (1990), the interval specific survival rate is defined as

$$
\begin{aligned}
\alpha_{k} & =P\left(T \geq t_{k} \mid T \geq t_{k-1}, x_{t}, z_{t}, v\right) \\
& =\exp \left[-\sum_{i=e l, e n, u} \int_{t_{k-1}}^{t_{k}} \theta_{i}\left(t \mid x_{k}, z_{k}, v_{i}\right) d t\right] \\
& =\exp \left[-\sum_{i=e l, e n, u} \exp \left(\beta_{i}^{\prime} x_{k}+\gamma_{i} z_{k}+v_{i}\right) \Lambda_{i, k}\right] \\
& =\prod_{i=e l, e n, u} \alpha_{i, k},
\end{aligned}
$$

where $\Lambda_{i, k}=\int_{t_{k-1}}^{t_{k}} \lambda_{i}(t) d t$ and $\alpha_{i, k}=\exp \left[-\exp \left(\beta_{i}^{\prime} x_{k}+\gamma_{i} z_{k}+v_{i}\right) \Lambda_{i, k}\right]$.

To find the contribution to the likelihood function from a job spell it is noted that the probability that a spell ends in interval $k$ is given by the conditional probability of failure in that interval times the probability that the spell survives until interval $k$, or $\left(1-\alpha_{k}\right) \prod_{j=1}^{k-1} \alpha_{j}$. Some spells are right censored and they contribute to the likelihood with the survivor function, $\prod_{j=1}^{k} \alpha_{j}$. Thus the contribution to the likelihood function from a job spell can be written

$$
\mathcal{L}_{e}\left(t \mid x_{t}, z_{t}, v_{e l}, v_{e n}, v_{u}\right)=\left(1-\alpha_{e l, k}\right)^{d_{e l}}\left(1-\alpha_{e l, k}\right)^{d_{e n}}\left(1-\alpha_{u, k}\right)^{d_{u}} \alpha_{k}^{1-d_{e l}-d_{e n}-d_{u}} \prod_{j=1}^{k-1} \alpha_{j}
$$

where $d_{e l}, d_{e n}$ and $d_{u}$ are destination state indicators. If the job spell is right censored then $d_{e l}=d_{e n}=d_{u}=0$. Instead of imposing a functional form on the baseline hazard, we allow for a flexible specification by simply estimating the interval specific baseline 
parameters $\Lambda_{i, k}$.

The wage of an individual at tenure $t$ is specified as

$$
\ln w_{t}=\zeta_{0}+\zeta_{1} t+\zeta_{2} x_{t}+\varepsilon_{t}
$$

where, for a given individual, the error term is composed of two components, an independently normally distributed idiosyncratic component and a random individual-specific effect,

$$
\varepsilon_{t}=u_{t}+v_{w}
$$

The likelihood contribution from a sequence of wage observations over a job spell is thus

$$
\mathcal{L}_{w}\left(w_{1}, \ldots, w_{t} \mid x_{1}, \ldots x_{t}, v_{w}\right)=\prod_{m=1}^{t} \varphi\left(\frac{\ln w_{m}-\zeta_{0}-\zeta_{1} m-\zeta_{2} x_{m}-v_{w}}{\sigma_{u}}\right)
$$

with $\sigma_{u}$ being the standard deviation of the idiosyncratic component, and $\varphi($.$) the stan-$ dard normal probability density function. Note that in this model, we would have had a simultaneity problem if we had allowed the wage to affect job durations as well. In the equation above, tenure affects the wage, but one might just as well have argued that the dependence should go the other way, or rather, both ways. However, the latter is not possible to identify in the present setup, and hence, a decision had to be made. ${ }^{5}$

To account for possible endogeneity of the home ownership variable, $z_{t}$, we simultaneously model the probability of being a home owner, the transition rates out of the job spell, and the wage. The probability of being home owner in year $t$ depends on explanatory variables, $x_{t}$ and $y_{t}$, and an unobserved component, $v_{h}$, and is specified as a logit model

$$
P\left(x_{t}, y_{t}, v_{h}\right)=P\left(z_{t}=1 \mid x_{t}, y_{t}, v_{h}\right)=\frac{\exp \left(\beta_{h}^{\prime} x_{t}+\alpha_{h}^{\prime} y_{t}+v_{h}\right)}{1+\exp \left(\beta_{h}^{\prime} x_{t}+\alpha_{h}^{\prime} y_{t}+v_{h}\right)},
$$

where $x_{t}$ are the same explanatory variables that are included in the duration model, and $y_{t}$ are variables that are included in the logit model, but not in the duration model. The

\footnotetext{
${ }^{5}$ We have also estimated a model with reverse causality between job duration and wages, but the results regarding home ownership still hold in that model, the results of which are available on request.
} 
corresponding contribution to the likelihood function from a job spell is

$$
\mathcal{L}_{h}\left(t \mid x_{t}, y_{t}, v_{h}\right)=\prod_{j=1}^{k} P\left(x_{j}, y_{t}, v_{h}\right)^{z_{j}}\left(1-P\left(x_{j}, y_{t}, v_{h}\right)\right)^{1-z_{j}}
$$

We assume that all sources of correlation between the three processes can be represented by the individual-specific heterogeneity terms. These terms are assumed to be time-invariant and hence constant across repeated spells for the same individual.

The unobserved heterogeneity is specified by the stochastic variables $v_{e n}, v_{e l}, v_{u}, v_{w}, v_{h}$, so the complete contribution to the likelihood function for each individual is

$$
\begin{aligned}
\mathcal{L}= & \int_{v_{e l}} \int_{v_{e n}} \int_{v_{u}} \int_{v_{w}} \int_{v_{h}} \mathcal{L}_{e}\left(t \mid x_{t}, z_{t}, v_{e}, v_{u}\right) \cdot \mathcal{L}_{w}\left(w_{1}, \ldots, w_{t} \mid x_{1}, \ldots x_{t}, v_{w}\right) \cdot \\
& \mathcal{L}_{h}\left(t \mid x_{t}, y_{t}, v_{h}\right) d F\left(v_{e l}, v_{e n}, v_{u}, v_{w}, v_{h}\right),
\end{aligned}
$$

where $F$ is the joint $\mathrm{CDF}$ for the unobserved heterogeneity, which remains to be specified. We use a flexible and widely applied specification of the distribution of the unobservables; it is assumed that $v_{e l}, v_{e n}, v_{u}, v_{w}$ and $v_{h}$ each can take two values, where one of the support points in each destination specific hazard is normalised to zero (i.e., $v_{e l}=0$, $v_{u}=0$ and $\left.v_{e n}=0\right)$, because the baseline hazard acts as a constant term in the hazard rates. Thus, there are 32 possible combinations of this trivariate unobserved heterogeneity distribution, each with an associated probability. For more details on this class of mixture distributions in duration models, see e.g. van den Berg (2001).

\subsection{Identification}

In order to identify the causal relation between home ownership and the outcomes of interest, we follow two identification strategies. The first identification strategy relies on multiple occurrences of job spells and ownership status for the individuals. This implies that we observe some individuals in several job spells, and in some they are home owners while in others they are not. Moreover, during a given job spell, some persons may change ownership status, in which case the argumentation from the 'timing-of-events' 
literature (Abbring \& Van den Berg (2003)) further adds to the identification of the model parameters. This identification approach has been used in a series of papers by Panis and coauthors (see e.g. Panis \& Lillard (1994), Upchurch et al. (2002), and Panis (2004)) and Munch et al. (2006).

We first describe the identification strategy that exploits multiple occurrences of both job spells and ownership status. Here, identification requires that we - for at least a subset of individuals - observe job spells both when the individual is a home owner and when the individual is a renter. The intuition for identification is spelled out in Panis (2004). In terms of our application, his argument goes as follows: suppose one observes only one respondent over a long period of time during which he switches home owner status. With a sample of one, there is no heterogeneity and no correlation across equations, so that equations are independent. The effect of home owner status on exit rates from employment is identified because of repeated observations on job spells and variations in home owner status. More generally, conditional on heterogeneity, the equations are independent, and identification rests on repeated outcomes with interpersonal variation in home owner status. In terms of interpersonal variation in home owner status, $6.8 \%$ (see Table 1) of the individuals we observe are observed both as renters and as home owners in different job spells. In addition, $18.8 \%$ change ownership status during a job spell, thus allowing separate identification of time-invariant unobserved heterogeneity and time-varying ownership effects, see Abbring \& Van den Berg (2003).

The second identification strategy uses exclusion restrictions, that is, we postulate the existence of a set of variables that affect home ownership but have no direct impact on labour market outcomes. In the literature on home ownership and labour markets, this strategy has been exploited by Van Leuvensteijn \& Koning (2004). Like Van Leuvensteijn \& Koning (2004) we use regional home ownership rate as an instrumental variable, which only affects home ownership status. In addition, we also include home owner status of the parents (in 1980) and the regional home owner rate in the municipality in which the individual was born. The regional home ownership rate will naturally affect the probability of being a home owner through a supply effect, but there is no reason to presume that 
this will have an impact on the individual's labour market outcomes, ceteris paribus. The same should hold for the regional home ownership rate in the region of birth. Finally, after conditioning on education and labour market experience, we find no reason why the parents' home ownership status should assert a current influence on labour market outcomes, given the past educational and labour market outcomes of the individual.

\section{Results}

In this section, we present the main results ${ }^{6}$. We first show the results from a model where we endogenize home ownership status and identify the home owner equation by exploiting the multiple spell features of our data and time variation in ownership status, that is, the first identification strategy outlined above. These results are reported in Table 2. Focusing first on explanatory variables other than home ownership, the effects are roughly in line with our expectations and the established wisdom. First, by comparing the two job-tojob transition rates, it is clear that younger workers are relatively more mobile, and that this age effect is more pronounced for the job change hazard that involves geographical mobility. Workers living outside Copenhagen (large city or small city) have a lower job change hazard rate for local jobs, but a higher job change hazard rate for non-local jobs. With respect to the unemployment risk, older workers have a higher hazard rate. Note, however, that this impact is conditional on years of working experience, and more working experience exerts a strong negative influence on the unemployment risk. Workers with further education have a markedly lower unemployment risk than workers with basic or vocational education. We do not present the estimated baseline hazards here. For all three transitions, we find negative duration dependence. ${ }^{7}$ This is in accordance with e.g. Farber (1999), who finds a similar pattern for job mobility in the US.

The wage equation has the traditional concave shape in working experience, and wages

\footnotetext{
${ }^{6}$ We do not present results for a model where we do not attempt to correct for the endogeneity of home owner status. These results show that home owners have $7 \%$ higher wages than renters, and that home owners are less likely to leave a current job spell for all three destinations. The results are of course available upon request.

${ }^{7}$ Results are available from the authors upon request.
} 
increase even more with job tenure in the sense that tenure is also a component in working experience. The results of the selection equation are also in line with what one would expect; the probability of being a home owner increases with e.g. age and family size.

Turning to the effect of home ownership, we find that owners are less likely to leave their job for unemployment - their unemployment risk is $29 \%$ lower than that of renters $(1-\exp [-0.3468] \approx 0.29)$. This result confirms the findings of Van Leuvensteijn \& Koning (2004) on Dutch data. However, Van Leuvensteijn \& Koning (2004) also found that home ownership does not affect the job change hazard rate. Since they do not distinguish between transitions into local jobs and non-local jobs, this result could hide a negative effect on job changes involving geographical mobility. Our results for the Danish labour market show that both job change hazard rates are lower for home owners, with the effect being strongest for transitions into non-local jobs as expected - the parameter estimates imply that home owners have a $14 \%$ (5\%) lower transition rate into a new job outside (inside) the local labour market. Recall that these results are completely consistent with the theoretical predictions outlined in section 2. Thus, our results suggest that owners set higher reservation wages for jobs outside the local labour market relative to renters, because they have to be compensated for transaction costs. The same result is found for local jobs, and this may be explained by the fact that employers invest more in firmspecific skills for owners.

In addition, home owners have a wage premium of $5.37 \%$ compared to renters even after correcting for endogeneity. Again, this result is in accordance with our theoretical considerations; owners stay longer in their jobs, and therefore they are more attractive to employers. As a consequence, employers may be willing to offer a wage premium in order to attract owners, and they may be more willing to invest in firm specific human capital for home owners.

Insert Table 2 about here

When we tried to estimate the full model, we experienced problems in terms of obtain- 
ing reliable estimates for the mass points and probabilities of the 32 different combinations of the 5 unobserved heterogeneity distributions. This is not unusual in these models. In order to make the model more tractable, we therefore restrict the correlation structure between the three hazard models to be perfect. This may appear to be overly restrictive. However, it still enables us to allow for completely flexible correlation between the wage equation, the home ownership status equation, and the transition rates out of a given job. In Table 2, we present the implied correlations between the three unobserved components. Although some of the correlations are significant, none of them are very large, implying that the selection bias that would have arisen if the selection process had been ignored is actually quite small.

In Table 3, we present a version of the model where we identify the home owner equation with instrumental variables as well as mulitple spells. The results do not differ much from those presented in Table 2, and we can therefore conclude that the results are robust to the choice of identification strategy. This could of course also be due to the instruments included. We did try different combinations of the instruments included in Table 3 (results are available on request), but they all produced results similar to those reported in Tables 2 and 3.

\section{Conclusion}

We have examined the causal impact of home ownership on job duration and wages. From a search theoretic perspective, we have argued that because of transaction costs employed home owners should have a lower transition rate into new non-local jobs, and therefore owners overall stay longer in their jobs. This makes owners more attractive for employers, i.e. employers are more likely to invest in firm-specific human capital and so owners are offered higher wages, and consequently they should also be less likely to leave the current job for other local jobs.

We have empirically examined these predictions using a detailed Danish micro data set. We have estimated a competing risks duration model for job spells with a distinction 
between transitions into new local jobs, new non-local jobs, and unemployment, and in addition we simultaneously estimate a standard human capital wage equation. Special attention has been devoted to identifying the causal linkage between home ownership and the labour market outcomes of interest.

Our empirical results are completely consistent with the theoretical predictions. Owners have lower transition rates into all three destinations than renters, and they also earn higher wages. The results contribute to the empirical literature on the labour market effects of home ownership in two ways. First, the reduced transition rates into new jobs are at odds with the results of Van Leuvensteijn \& Koning (2004) for the Dutch labour market, but consistent with search theory. Second, the impact of home ownership on wages has not been the subject of intense scrutiny, and to the best of our knowledge it has never been studied in empirical models where the selection into home ownership has been carefully taken into account.

In terms of the arguments mentioned in the introduction, where positive externalities associated with home ownership has been used to argue for favourable tax treatments of home owners, our results suggest that there are also significant labour market gains associated with home ownership. Since these gains are private, and since they might even impose negative externalities on others (because with a given budget constraint, training home owners implies that renters do not receive training), we do not see the results as strengthening the case for favourable tax treatment of home ownership.

\section{References}

[1] Abbring, J. \& G. van den Berg (2003). "The Non-Parametric Identification of Treatment Effects in Duration Models", Econometrica, 71, 1491-1517.

[2] Andersen, A.K. (2000). Commuting Areas in Denmark, AKF Forlaget, Copenhagen.

[3] Coulson, N.E. \& L.M. Fischer (2002). "Tenure Choice and Labour Market Outcomes", Housing Studies, 17(1), 35-49. 
[4] Danish Economic Council (2002). Danish Economy, Autumn 2002, Copenhagen.

[5] Dietz, R.D. \& D.R. Haurin (2003). "The Social and Private Micro-Level Consequences of Homeownership", Journal of Urban Economics, 54, 401-450.

[6] Farber, H. S. (1999). "Mobility and Stability: The Dynamics of Job Change in Labor Markets," The Handbook of Labor Economics, Orley Ashenfelter and David Card (eds.) Vol 3, Elsevier Science.

[7] Gardner, J, G. Pierre \& A. Oswald (2000). "Moving for Job Reasons", Working Paper, University of Warwick.

[8] Green, R. \& P. Hendershott (2001a). "Home Ownership and the Duration of Unemployment: A Test of The Oswald Hypothesis", Working paper.

[9] Green, R. \& P. Hendershott (2001b). "Home Ownership and Unemployment in the US", Urban Studies, 38, 1501-1520.

[10] Hendershott, P. \& M. White (2000). "The Rise and Fall of Housing's Favored Investment Status", Journal of Housing Research, 11, 257-275.

[11] Munch, J. \& M. Svarer (2002). "Rent Control and Tenancy Duration", Journal of Urban Economics , 52, 542-560.

[12] Munch, J., M. Rosholm \& M. Svarer (2006). "Are Home Owners Really More Unemployed?", Economic Journal, forthcoming.

[13] Nickell, S. \& R. Layard (1999). "Labour Market Institutions and Economic Performance" in A. Ashenfelter \& D. Card, eds., Handbook of Labor Economics, Vol. 3, North Holland, Amsterdam.

[14] OECD (2000). Employment Outlook, OECD, Paris.

[15] Oswald, A. (1996). "A Conjecture of the Explanation for High Unemployment in the Industrialized Nations: Part I", Warwick University Economic Research Paper No. 475 . 
[16] Panis, C. \& L. Lillard (1994). "Health Inputs and Child Mortality: Malaysia", Journal of Health Economics, 13, 455-489.

[17] Panis, C. (2004). "Microsimulations in the Presence of Unobserved Heterogeneity", Draft, RAND Corporation.

[18] Rosholm, M. \& M. Svarer (2004), "Endogenous Wage Dispersion and Job Turnover in a Search-Matching Model", Labour Economics, 11, 623-645.

[19] Svarer, M, M. Rosholm \& J. Munch (2005). "Rent Control and Unemployment Duration", Journal of Public Economics, 89, 2165-2181.

[20] Upchurch, D.M., L. Lillard, C. Panis (2002). "Nonmarital Childbearing: Influences of Education, Marriage, and Fertility", Demography, 39(2), 311-329.

[21] van den Berg, G. (2001). "Duration Models: Specification, Identification, and Mulitple Durations", in J.J. Heckman \& E. Leamer, eds. Handbook of Econometrics, Vol. V, North Holland, Amsterdam.

[22] Van Leuvensteijn, M. \& P. Koning (2004). "The Effects of Home Ownership on Labour Mobility in the Netherlands", Journal of Urban Economics , 55, 580-596. 


\section{A Appendix: Tables}

TABLE 1

Summary STATISTICS

\begin{tabular}{lrrrrrr}
\hline \hline & \multicolumn{2}{c}{ All } & \multicolumn{3}{c}{ Owners } & \multicolumn{2}{c}{ Renters } \\
\hline Variables & Mean & Stdv. & Mean & Stdv. & Mean & Stdv. \\
\hline Home Owner & 0.58 & 0.49 & & & & \\
Age 18-24 & 0.14 & 0.35 & 0.04 & 0.19 & 0.30 & 0.45 \\
Age 25-29 & 0.15 & 0.36 & 0.11 & 0.31 & 0.21 & 0.41 \\
Age 30-39 & 0.31 & 0.46 & 0.34 & 0.47 & 0.27 & 0.44 \\
Age 40-49 & 0.22 & 0.41 & 0.29 & 0.45 & 0.13 & 0.33 \\
Age 50-59 & 0.15 & 0.35 & 0.20 & 0.40 & 0.07 & 0.26 \\
Female & 0.42 & 0.49 & 0.44 & 0.49 & 0.40 & 0.49 \\
Children 0-17 years & 0.23 & 0.42 & 0.29 & 0.45 & 0.15 & 0.35 \\
Two adults & 0.67 & 0.46 & 0.86 & 0.34 & 0.40 & 0.49 \\
Copenhagen & 0.23 & 0.42 & 0.17 & 0.37 & 0.31 & 0.46 \\
Large city & 0.14 & 0.35 & 0.13 & 0.33 & 0.16 & 0.36 \\
Small city & 0.62 & 0.48 & 0.69 & 0.46 & 0.52 & 0.49 \\
Basic education & 0.33 & 0.47 & 0.26 & 0.43 & 0.43 & 0.49 \\
Vocational education & 0.40 & 0.49 & 0.44 & 0.49 & 0.35 & 0.47 \\
Further education & 0.26 & 0.43 & 0.29 & 0.45 & 0.21 & 0.41 \\
Experience (years) & 13.3 & 9.1 & 16.2 & 8.3 & 9.5 & 7.6 \\
Tenure (years) & 1.3 & 1.6 & 1.8 & 1.7 & 1.1 & 1.4 \\
Log wage (/10) & 5.08 & 0.41 & 5.18 & 0.36 & 4.94 & 0.43 \\
Owner share, region of residence & 0.58 & 0.13 & 0.60 & 0.13 & 0.54 & 0.12 \\
Owner share, region of birth & 0.49 & 0.22 & 0.51 & 0.21 & 0.46 & 0.23 \\
Parents' home owner status 1980 & 0.57 & 0.49 & 0.58 & 0.49 & 0.57 & 0.49 \\
\hline Number of individuals & & & & & & 17,297 \\
Number of spells & & & & & & 29,878 \\
Mean duration of spell (years) & & & & & & 2.78 \\
Proportion of spells: & & & & & & 0.33 \\
- right-censored spells & & & & & & 0.40 \\
- end with job change locally & & & & & & 0.14 \\
- end with job change non-locally & & & & & & 0.188 \\
- end with unemployment & Persons with change of home owner status & (\%) & & & & \\
Persons with change of home owner status & and more than 1 spell & $(\%)$ & 0.068 \\
\hline
\end{tabular}


TABLE 2

ESTIMATION RESULTS

\begin{tabular}{|c|c|c|c|c|c|c|}
\hline \multirow[b]{2}{*}{ Variables } & \multicolumn{2}{|c|}{$\begin{array}{c}\text { Job change } \\
\text { hazard, no mobility }\end{array}$} & \multicolumn{2}{|c|}{$\begin{array}{c}\text { Job change } \\
\text { hazard, with mobility }\end{array}$} & \multicolumn{2}{|c|}{$\begin{array}{l}\text { Unemployment } \\
\text { hazard }\end{array}$} \\
\hline & Coeff. & Std. err. & Coeff. & Std. err. & Coeff. & Std. err. \\
\hline Home ownership & -0.0587 & 0.0245 & -0.1597 & 0.0401 & -0.3468 & 0.0597 \\
\hline Age $19-24$ & 0.3472 & 0.0395 & 0.6666 & 0.0630 & -0.6235 & 0.0831 \\
\hline Age $25-29$ & 0.0488 & 0.0317 & 0.3315 & 0.0510 & -0.3454 & 0.0718 \\
\hline Age $40-49$ & -0.1978 & 0.0317 & -0.1885 & 0.0531 & 0.2059 & 0.0746 \\
\hline Age $50+$ & -0.2838 & 0.0430 & -0.5172 & 0.0850 & 0.7257 & 0.0887 \\
\hline Female & -0.0045 & 0.0200 & -0.4632 & 0.0345 & 0.1474 & 0.0493 \\
\hline Children $0-17$ years & 0.0388 & 0.0267 & -0.0953 & 0.0447 & -0.0140 & 0.0670 \\
\hline Two adults & -0.0709 & 0.0243 & -0.0483 & 0.0406 & -0.3207 & 0.0556 \\
\hline Large city & -0.3928 & 0.0321 & 1.3110 & 0.0683 & 0.2656 & 0.0765 \\
\hline Small city & -0.4417 & 0.0226 & 1.4523 & 0.0597 & 0.0531 & 0.0607 \\
\hline Basic education & -0.0594 & 0.0230 & -0.1019 & 0.0373 & 0.0843 & 0.0528 \\
\hline Further education & -0.1978 & 0.0267 & 0.0721 & 0.0440 & -1.0689 & 0.0752 \\
\hline Experience/10 & 0.0553 & 0.0526 & 0.1044 & 0.0893 & -0.9309 & 0.1150 \\
\hline Experience squared/100 & -0.0286 & 0.0152 & -0.0642 & 0.0269 & 0.0935 & 0.0352 \\
\hline$v_{h}^{1}$ & -7.3118 & 0.0746 & & & & \\
\hline$v_{h}^{2}$ & -2.1912 & 0.0591 & & & & \\
\hline$v_{w}^{n}$ & 4.8949 & 0.0036 & & & & \\
\hline$v_{w}^{2}$ & 5.3353 & 0.0037 & & & & \\
\hline$v_{e n}^{2}$ & 2.3898 & 0.0585 & & & & \\
\hline$v_{e l}^{2}$ & 3.1652 & 0.0751 & & & & \\
\hline$v_{u}^{2}$ & 1.8440 & 0.0431 & & & & \\
\hline $\mathrm{p}_{1}^{u}\left(v_{h}^{1}, v_{w}^{1}, v_{e .}^{1}\right)$ & 0.2294 & 0.0043 & & & & \\
\hline $\mathrm{p}_{2}\left(v_{h}^{1}, v_{w}^{1}, v_{e .}^{2}\right)$ & 0.0296 & 0.0022 & & & & \\
\hline $\mathrm{p}_{3}\left(v_{h}^{2}, v_{w}^{1}, v_{e .}^{1}\right)$ & 0.4146 & 0.0050 & & & & \\
\hline $\mathrm{p}_{4}\left(v_{h}^{2}, v_{w}^{1}, v_{e .}^{2}\right)$ & 0.0386 & 0.0026 & & & & \\
\hline $\mathrm{p}_{5}\left(v_{h}^{1}, v_{w}^{2}, v_{e .}^{1}\right)$ & 0.0884 & 0.0031 & & & & \\
\hline $\mathrm{p}_{6}\left(v_{h}^{1}, v_{w}^{2}, v_{e .}^{2}\right)$ & 0.0086 & 0.0014 & & & & \\
\hline $\mathrm{p}_{7}\left(v_{h}^{2}, v_{w}^{2}, v_{e .}^{1}\right)$ & 0.1718 & 0.0039 & & & & \\
\hline $\mathrm{p}_{8}\left(v_{h}^{2}, v_{w}^{2}, v_{e .}^{2}\right)$ & 0.0190 & 0.0019 & & & & \\
\hline $\operatorname{Corr}\left(v_{h}, v_{w}\right)$ & 0.0261 & 0.0115 & & & & \\
\hline $\operatorname{Corr}\left(v_{h}, v_{e .}\right)$ & -0.0309 & 0.0149 & & & & \\
\hline $\operatorname{Corr}\left(v_{e}, v_{w}\right)$ & -0.0001 & 0.0135 & & & & \\
\hline
\end{tabular}

Note: Bold numbers indicate a significant parameter estimate $(5 \%$ level). Since the hazard models are perfectly correlated they are represented by $\mathrm{v} e$.in the probabilities and correlations. The standard error for the correlation coefficient and mass point probabilities has been calculated based on 1,000 drawings from the multivariate normal distribution with mean and covariance matrix set equal to the estimated parameter vector and covariance matrix 
TABle 2 CONTINUEd

\begin{tabular}{lrrrr}
\hline \hline & \multicolumn{2}{c}{ Wage equation } & \multicolumn{2}{c}{ Selection equation } \\
Variables & Coeff. & Std. err. & Coeff. & Std. err. \\
\hline Home ownership & $\mathbf{0 . 0 5 3 7}$ & 0.0020 & & \\
Age 19-24 & $\mathbf{- 0 . 2 3 1 7}$ & 0.0031 & $\mathbf{- 1 . 3 0 9 7}$ & 0.0462 \\
Age 25-29 & $\mathbf{- 0 . 0 4 2 7}$ & 0.0028 & $\mathbf{- 0 . 6 1 5 6}$ & 0.0369 \\
Age 40-49 & $\mathbf{- 0 . 0 0 5 3}$ & 0.0023 & $\mathbf{0 . 0 9 2 0}$ & 0.0413 \\
Age 50 + & $\mathbf{- 0 . 0 1 3 3}$ & 0.0030 & $\mathbf{0 . 3 2 0 3}$ & 0.0556 \\
Female & $\mathbf{- 0 . 1 6 8 2}$ & 0.0015 & $\mathbf{0 . 3 1 5 2}$ & 0.0249 \\
Children 0-17 years & $\mathbf{0 . 0 0 8 8}$ & 0.0022 & $\mathbf{0 . 5 1 8 3}$ & 0.0344 \\
Two adults & $\mathbf{0 . 0 3 2 6}$ & 0.0020 & $\mathbf{2 . 1 3 0 4}$ & 0.0283 \\
Large city & $\mathbf{- 0 . 0 7 2 8}$ & 0.0022 & $\mathbf{0 . 3 8 2 1}$ & 0.0365 \\
Small city & $\mathbf{- 0 . 0 9 1 2}$ & 0.0016 & $\mathbf{1 . 0 7 9 4}$ & 0.0274 \\
Basic education & $\mathbf{- 0 . 1 7 3 6}$ & 0.0017 & $\mathbf{- 0 . 5 3 0 6}$ & 0.0288 \\
Further education & $\mathbf{0 . 1 7 8 7}$ & 0.0018 & $\mathbf{0 . 2 2 6 2}$ & 0.0322 \\
Experience/10 & $\mathbf{0 . 2 1 9 8}$ & 0.0037 & $\mathbf{3 . 0 4 6 8}$ & 0.0660 \\
Experience squared $/ 100$ & $\mathbf{- 0 . 0 4 1 1}$ & 0.0010 & $\mathbf{- 0 . 6 0 7 5}$ & 0.0199 \\
Tenure/10 & $\mathbf{0 . 0 9 3 2}$ & 0.0053 & & \\
Var(u) & $\mathbf{- 2 . 7 0 2 4}$ & 0.0018 & & \\
\hline Note: Bold numbers indicate a significant parameter estimate $(5 \%$ level $)$ & & \\
\hline
\end{tabular}

Note: Bold numbers indicate a significant parameter estimate ( $5 \%$ level). 
TABLE 3

ESTIMATION RESULTS -INSTRUMENTS

\begin{tabular}{|c|c|c|c|c|c|c|}
\hline \multirow[b]{2}{*}{ Variables } & \multicolumn{2}{|c|}{$\begin{array}{c}\text { Job change } \\
\text { hazard, no mobility }\end{array}$} & \multicolumn{2}{|c|}{$\begin{array}{c}\text { Job change } \\
\text { hazard, with mobility }\end{array}$} & \multicolumn{2}{|c|}{$\begin{array}{l}\text { Unemployment } \\
\text { hazard }\end{array}$} \\
\hline & Coeff. & Std. err. & Coeff. & Std. err. & Coeff. & Std. err. \\
\hline Home ownership & -0.0640 & 0.0244 & -0.1776 & 0.0399 & -0.3847 & 0.0595 \\
\hline Age 19-24 & 0.3628 & 0.0395 & 0.6403 & 0.0628 & -0.6259 & 0.0829 \\
\hline Age $25-29$ & 0.0624 & 0.0316 & 0.3227 & 0.0508 & -0.3399 & 0.0719 \\
\hline Age $40-49$ & -0.1985 & 0.0317 & -0.2041 & 0.0530 & 0.1898 & 0.0747 \\
\hline Age $50+$ & -0.2927 & 0.0430 & -0.5250 & 0.0849 & 0.6970 & 0.0889 \\
\hline Female & -0.0060 & 0.0199 & -0.4623 & 0.0342 & 0.1507 & 0.0492 \\
\hline Children $0-17$ years & 0.0410 & 0.0267 & -0.0883 & 0.0446 & -0.0019 & 0.0670 \\
\hline Two adults & -0.0733 & 0.0243 & -0.0540 & 0.0405 & -0.3141 & 0.0557 \\
\hline Large city & -0.3933 & 0.0321 & 1.2826 & 0.0681 & 0.2437 & 0.0764 \\
\hline Small city & -0.4372 & 0.0225 & 1.4310 & 0.0596 & 0.0524 & 0.0608 \\
\hline Basic education & -0.0601 & 0.0229 & -0.1202 & 0.0371 & 0.0819 & 0.0527 \\
\hline Further education & -0.1883 & 0.0266 & 0.0543 & 0.0436 & -1.0608 & 0.0754 \\
\hline Experience/10 & 0.0845 & 0.0525 & 0.0887 & 0.0891 & -0.8910 & 0.1147 \\
\hline Experience squared/100 & -0.0338 & 0.0152 & -0.0577 & 0.0269 & 0.0897 & 0.0351 \\
\hline$v_{h}^{1}$ & -10.1338 & 0.1004 & & & & \\
\hline$v_{h}^{2}$ & -5.0737 & 0.0846 & & & & \\
\hline$v_{w}^{n}$ & 4.8953 & 0.0036 & & & & \\
\hline$v_{w}^{2}$ & 5.3361 & 0.0037 & & & & \\
\hline$v_{e n}^{2}$ & 2.4424 & 0.0605 & & & & \\
\hline$v_{e l}^{2}$ & 3.2331 & 0.0766 & & & & \\
\hline$v_{u}^{2}$ & 1.9074 & 0.0452 & & & & \\
\hline $\mathrm{p}_{1}\left(v_{h}^{1}, v_{w}^{1}, v_{e .}^{1}\right)$ & 0.2339 & 0.0044 & & & & \\
\hline $\mathrm{p}_{2}\left(v_{h}^{1}, v_{w}^{1}, v_{e}^{2}\right)$ & 0.0297 & 0.0022 & & & & \\
\hline $\mathrm{p}_{3}\left(v_{h}^{2}, v_{w}^{1}, v_{e .}^{1}\right)$ & 0.4111 & 0.0051 & & & & \\
\hline $\mathrm{p}_{4}\left(v_{h}^{2}, v_{w}^{1}, v_{e}^{2}\right)$ & 0.0393 & 0.0026 & & & & \\
\hline $\mathrm{p}_{5}\left(v_{h}^{1}, v_{w}^{2}, v_{e}^{1}\right)$ & 0.0881 & 0.0029 & & & & \\
\hline $\mathrm{p}_{6}\left(v_{h}^{1}, v_{w}^{2}, v_{e}^{2}\right)$ & 0.0086 & 0.0014 & & & & \\
\hline $\mathrm{p}_{7}\left(v_{h}^{2}, v_{w}^{2}, v_{e}^{1}\right)$ & 0.1707 & 0.0038 & & & & \\
\hline $\mathrm{p}_{8}\left(v_{h}^{2}, v_{w}^{2}, v_{e}^{2}\right)$ & 0.0188 & 0.0019 & & & & \\
\hline $\operatorname{Corr}\left(v_{h}, v_{w}\right)$ & 0.0313 & 0.0118 & & & & \\
\hline $\operatorname{Corr}\left(v_{h}, v_{e .}\right)$ & -0.0267 & 0.0142 & & & & \\
\hline $\operatorname{Corr}\left(v_{w}, v_{e .}\right)$ & -0.0016 & 0.0132 & & & & \\
\hline
\end{tabular}

Note: Bold numbers indicate a significant parameter estimate $(5 \%$ level). Since the hazard models are perfectly correlated they are represented by $v e$.in the probabilities and correlations. The standard error for the correlation coefficient and mass point probabilities has been calculated based on 1,000 drawings from the multivariate normal distribution with mean and covariance matrix set equal to the estimated parameter vector and covariance matrix. 
Table 3 Continued

\begin{tabular}{lrrrr}
\hline \hline & \multicolumn{2}{c}{ Wage equation } & \multicolumn{2}{c}{ Selection equation } \\
Variables & Coeff. & Std. err. & Coeff. & Std. err. \\
\hline Home ownership & $\mathbf{0 . 0 5 3 1}$ & 0.0020 & & \\
Age 19-24 & $\mathbf{- 0 . 2 3 7 2}$ & 0.0031 & $\mathbf{- 1 . 4 8 4 1}$ & 0.0476 \\
Age 25-29 & $\mathbf{- 0 . 0 4 2 6}$ & 0.0028 & $\mathbf{- 0 . 6 2 9 6}$ & 0.0372 \\
Age 40-49 & $\mathbf{- 0 . 0 0 5 4}$ & 0.0023 & $\mathbf{0 . 3 2 6 1}$ & 0.0460 \\
Age 50 & $\mathbf{- 0 . 0 1 3 4}$ & 0.0030 & $\mathbf{0 . 5 9 4 9}$ & 0.0686 \\
Female & $\mathbf{- 0 . 1 6 8 1}$ & 0.0015 & $\mathbf{0 . 2 6 5 4}$ & 0.0248 \\
Children 0-17 years & $\mathbf{0 . 0 0 8 7}$ & 0.0022 & $\mathbf{0 . 4 5 5 2}$ & 0.0344 \\
Two adults & $\mathbf{0 . 0 3 2 7}$ & 0.0020 & $\mathbf{2 . 2 7 0 5}$ & 0.0290 \\
Large city & $\mathbf{- 0 . 0 7 2 8}$ & 0.0022 & $\mathbf{0 . 5 8 1 1}$ & 0.0372 \\
Small city & $\mathbf{- 0 . 0 9 1 2}$ & 0.0016 & $\mathbf{0 . 1 3 9 5}$ & 0.0330 \\
Basic education & $\mathbf{- 0 . 1 7 3 6}$ & 0.0017 & $\mathbf{- 0 . 6 2 0 7}$ & 0.0288 \\
Further education & $\mathbf{0 . 1 7 8 8}$ & 0.0018 & $\mathbf{0 . 1 3 3 6}$ & 0.0319 \\
Experience/10 & $\mathbf{0 . 2 1 9 9}$ & 0.0037 & $\mathbf{2 . 9 1 3 2}$ & 0.0666 \\
Experience squared/100 & $\mathbf{- 0 . 0 4 1 2}$ & 0.0010 & $\mathbf{- 0 . 5 7 4 0}$ & 0.0199 \\
Tenure/10 & $\mathbf{0 . 0 9 3 6}$ & 0.0053 & & \\
Var(u) & $\mathbf{- 2 . 7 0 2 3}$ & 0.0018 & & \\
Owner share, reg. of residence & & & $\mathbf{0 . 0 5 7 1}$ & 0.0012 \\
Owner share, reg. of birth & & & $\mathbf{0 . 0 0 2 8}$ & 0.0005 \\
Owner share, reg. of birth missing & & & 0.0577 & 0.7162 \\
Parents' owner status 1980 & & $\mathbf{0 . 3 8 2 6}$ & 0.0279 \\
Parents' owner status missing & & & $\mathbf{- 0 . 1 8 2 3}$ & 0.0479 \\
\hline Note: Bold numbers indicate a significant parameter estimate $(5 \%$ level). & & & \\
\end{tabular}

